ABSTRACT

The Expansion of Theatrical Space and the Role of the Spectator One of the theatre and performance conventions that has been challenged by the application of technology is that of space. Theatrical space has been "expanded" through the application of technology and its artefacts. However, it is not really

clear what is meant by "expansion", as it means different things according to different authors and these divergent meanings often lead to misunderstandings. In this article, I will demonstrate the need for a more nuanced understanding of what the expansion of theatrical space means and its impact on the concept of spectatorship.

The analysis will be based on three distinct forms of digital performance where spatial expansion has been an issue; these are three categories that also mark the heterogeneity and dynamism of the convergence of performance and technology: multimedia performance, telematic performance and pervasive performance. Through an analysis of specific cases across the categories, I aim to show how the expansion of space implies a more participatory stance in the role of the spectator.

Keywords: digital performance, multimedia, participation, pervasive performance, space expansion, spectator, telematics.

BIOGRAPHY

Elena Pérez is a researcher currently taking her $\mathrm{PhD}$ in the Department of Art and Media Studies at the Norwegian University of Science and Technology (NTNU), where she is looking at how digital media impacts contemporary performance. More specifically, how digital media challenge theatrical conventions in multimedia, telematic and pervasive performance.

elena.perez@ntnu.no

\section{The Expansion of Theatrical Space and the Role of the Spectator}

\author{
ELENA PÉREZ
}

This article investigates performance works at the convergence of digital media and contemporary performance and the ways in which they expand theatrical space. Here, digital media refers to digitized (as opposed to analogue) content such as text, audio, video, graphics, metadata, etc. that can be stored and transmitted over the Internet and computer networks. Contemporary performance refers to performance works that combine different artistic traditions in one performance event - such as experimental theatre and dance, video art, visual art, music composition and performance art - and which also engage with social and political realities. The convergence of digital media with contemporary performance has produced a significant body of digital performance practices ${ }^{l}$ that are said to challenge and reconfigure conventional theatrical notions of space, time, body/physicality, audience-performer relationship and interactivity, as well as the technologies themselves, through their applications to artistic productions. This article will investigate how and to what ends technological artefacts have challenged and reconfigured performance space and suggests that the expansion of space relates to the increase of the agency of the spectator.

To mark the heterogeneity and dynamism of this arena today, I suggest three distinct categories of digital performance where space expansion has been an issue. The first category, multimedia performance, refers to "any performance that employs film, video or computer-generated imagery alongside live performance." ${ }^{2}$ Here, it also refers to per-

formances with a traditional relationship between performer-spectator, where the audience watches a staged performance without actively taking part in it as performers. The second category, telematic performance, includes performances that connect remote actors and performance spaces through networked communication technologies. The final category, pervasive performance, includes mixed media events that combine gameplay ${ }^{3}$ with performance and is used as a platform for potential collaborative art making in public spaces. These are events with a playing audience where, thanks to mobile media, the action moves from the self-contained internal space of the theatre venue out into the everyday environments of its users.

As we see, this landscape of digital performance is vast and varied. The conventional theatre space has been said to "expand" in each of these forms, but the concept is used, as I will argue, in a loose and general way. For example, in multimedia performance, space is expanded metaphorically; in telematic performance it is expanded psychologically, whereas in pervasive performance, it is expanded in a literal, territorial sense.

This lack of clarity as to when space can be said to have been expanded needs to be addressed. As proceed to clarify how exactly space is expanded in these three categories, I hope to, simultaneously, be able to examine how the role of the audience changes as a result of this expansion. In this sense, I aim to gain a better understanding of a question central to theatre and performance studies; as Christopher 
Balme puts it, "the close relationship between stage forms and spectatorial attitudes". ${ }^{4}$

\section{THE EXPANSION OF THEATRICAL SPACE AND} SPECTATORSHIP

Theatrical space refers to the spatial structure that regulates the relationship between actors and spectators. ${ }^{5}$ The concept implies a building, or a fixed area, where participants are located. Inside the theatre building, this space can be organized in various ways that structure the encounter between actors and spectators, going from strict forms that demarcate and divide the space for spectators, to more flexible forms where spectators can move freely and choose their point of view. Multimedia performance can adopt any of these structural forms by adding technology in the demarcated stage areas. The expansion of theatrical space here refers to the ways in which new spaces can be incorporated into the existing theatrical space through technology. Steve Dixon, for instance, has argued that additional spaces can be created through projections, even though these are two-dimensional. ${ }^{6}$

Other theatre forms such as pervasive performance, street theatre and even some forms of applied theatre do not depend on fixed architectural structures and take place outside of the theatre building and institution. Marvin Carlson has called these expanded spaces "ludic spaces", which are "permanent or temporary grounds for the encounter of spectators and performers". ${ }^{7}$ However, theatrical spaces are also ludic spaces, as they are spaces where play takes place. In this article, I will refer to spaces outside of enclosed theatre venues as 'expanded' theatrical spaces. For example, telematic and pervasive performance connect and take place in various spaces, both theatrical (inside a theatre house) and expanded (public spaces or private homes), thanks to the application of networked technology and ubiquitous media.

In this situation of proliferation of spaces for performance - theatrical and expanded, it is becoming increasingly difficult to locate the artwork, as i is not unified in one location, but it is dispersed and distributed across expanded spaces. Christopher Balme has proposed the concept of "distributed aes- thetics" to describe the composition of these type of performances. ${ }^{8} \mathrm{He}$ aims to open up the concepts of theatrical and expanded space to incorporate virtual environments and proposes the broad concept of the "theatrical public sphere" to be able to encompass the variety of theatre spaces, which consist in combination of physical spaces (theatrical and expanded) with media sites (going from Internet sites to films and TV) across the mediasphere. Balme's concept is useful as it points to how widespread and scattered - but yet connected - the spaces for performance can be in the media age. However, his attempt at opening up ends up opening too much, so to speak, as it becomes impossible to trace a pertoo broad concept of the public sphere. In the work that I will be analysing in this article, the distributed spaces for performance do not disperse as much as Balme thinks, as these performances are always still connected to a main, physical event and depend on it. The concept of distributed aesthetics is productive, though, because it breaks the idea of a central, unified space into smaller and scattered, distributed spaces, and brings in the possibility of being together while still being apart.' In other words, there can still be a relationship between performers and spectators without the need to share one and the same

But what criteria can we use to locate the artwork that takes place in multiple locations?

Steve Dixon has proposed using the figure of the spectator as a criterion for establishing theatrical and expanded spaces. He has argued that "networked technologies certainly link and connect different places enabling remote communication, image an sound transfer, and so on, but the physical location of the participant remains the overriding spatial position of both the artwork and the viewing subject".$^{10}$ In his view, the criterion to locate the artwork is the physical location of the spectator, rathe than, for example, the physical location of the performer, a criterion presented by Scott DeLahunta earlier. ${ }^{11}$ This appreciation is crucial as it links the expansion of space to the figure of the spectator, delimiting it to spaces that can "contain" spectators or where spectators are "present".

When talking about telematic performance and how a sense of presence is conveyed in remote environments, media scholar Katherine Hayles has argued that presence is no longer determined by the physical location of bodies, but rather by the actions that bodies are able to perform in responsive environments. ${ }^{12}$ Hayles' understanding refers to remote dancers (professional performers) dancing 'together' in a screen interface system, rather than to spectators. However, Hayles' concept can be transferred to the context of the audience as it helps to expand Dixon's role of the spectator from a participant "located" in an environment to a participan that "acts" in an environment that "supports" those actions. Support here means that the environment is able to accommodate the actions and respond to them in an interactive way; the criterion to define the performance space is thus not where the spectator is physically located, but in the expanded environments that afford spectators' actions.

Understanding expanded theatrical spaces as the spaces where participants are able to perform actions is assumed in the work of Steve Benford and Gabriella Giannachi with Mixed Reality performance (or MRP, corresponding to what I call pervasive performance) ${ }^{13}$ MRP generates hybrid realities that span physical environments and virtual worlds. In their view, it is participants who, by their actions (a sum of actions would be what they call "trajectories") ${ }^{14}$, generate this hybrid space as they advance in the performance. They also point to the need for collaboration and negotiation between participants located in physical environments and participants located in the virtual worlds to be able to progress in the performance. ${ }^{15}$ In this sense, space expansion also has to do with the collaboration between the participants located in the different expanded spaces. Therefore, when we talk about the expansion of theatrical space, we see that the limits around the concept of spectatorship are brought forward.

What, then, is the role of the spectator if we compare the more traditional spectatorship in multimedia performance of "spectator as viewers" and the expanded theatrical spaces of telematic and pervasive performance that afford a more active role of "spectator as agents"? How do the different expansions of space re-configure spectatorship?
MULTIMEDIA PERFORMANCE:THE SPECTATOR AS VIEWER

Multimedia performance generally refers to any performance that employs film, video or computer-generated imagery alongside a live performance. In multimedia performance, the audience watches a staged performance without actively taking part in it as performers. Within this category, I include performances that follow dramatic forms where a message is conveyed and communicated to an audience - aligned with the Aristotelian tradition, as well as postdramatic practices ${ }^{16}$ where the focus is in simultaneous dramaturgy, appealing to the unconscious by generating gestures, scenes and emotions, rather than aiming at communicating a clear and fixed message. Practitioners engaged in multimedia performance are, among others, Robert Lepage, The Wooster Group, Robert Wilson and The Builders Association. ${ }^{17}$

Steve Dixon has argued that the use of digital media onstage - screens and projections - enables practitioners to "frame additional spaces in two dimensions (even when the computer images on them are rendered as three-dimensional simulations)" ${ }^{18}$ In his view, "despite the flatness of the screen frame, projected media can in one important sense offe far more spatial possibilities than three-dimensional theatre space." ${ }^{19}$ The additional space that Dixo refers to is the in between space that is created when the projected image and stage action are combined which affords new meanings. I want to make a crucial point here, which is how this is not a topological space in itself as much as it is a set of strategies. What makes us think of the relationship between technology and traditional theatre elements a mainly spatial is the importance of their arrangement in terms of composition on a stage and how the space left in between them seems to be filled by meaning. This is easily perceived when images are projected as background, either occupying the whole area or parts of it, while stage action is simultaneously located in front, as seen in Figure 1; or when the projections are located before the stage action, involving the actors, as shown in Figure 2. In this way, those imperceptible relationships are made explicit and brought forward to the eye of the spectator and the metaphor of space is especially apt 
to illustrate the site where perception and meaning creation takes place. So when Dixon claims there is an expansion of space thanks to the use of medi onstage, what he is really saying is that there is an expansion of new strategies for meaning making thanks to the combination of media and stage action. In this sense, it is key to note that in multimedia performance, there is not a literal expansion of space, but rather, a metaphorical one.

The consequences of this type of expansion for the audience are minor. The audience members remain in the traditional role of the "spectator-as-viewer" whose job is to decipher and understand a performance that uses new digital vocabulary to convey and communicate meaning, as is common in traditional aesthetics. The role of the performer remains central, but nevertheless having to adapt to the new tools and having to share the stage with projected elements. In some cases, his/ her role is more central than the projection, as in the scene of The Andersen Project (2006), where the projections frame and support the stage action. In other cases, the performer's role is relegated to a secondary position, as in the scene in Ghost Road (2013), where the projected actor is larger and brighter than the physical actor (and gets more stage time). AS USER

Telematic performance uses telecommunication networks to establish links between remote spaces, using the Internet to transmit images and sound between two or more sites to create a shared performance event. There are typically two version of telematic performance. One is high-tech; it use teleconferencing to connect full body performers in two or three dimensions, has high resolution, and is expensive and cumbersome - so technically complex that it needs to be mounted in a fixed location. The other applies low-tech, domestic technologies such as Skype, has low-resolution, is cheap and pervasive - technically so simple that it can be used anywhere. ${ }^{20}$

Contemporary examples of high-tech telematic performance are seldom presented in theatre venues, as normal theatre houses often cannot provide the appropriate technological means necessary. They either are presented in technology-oriented events or remain within research institutions. Examples are Panorama: a Multimedia Happening (2009) by Smith/Wymore Disappearing Acts, linking dancer in Berkeley and Illinois, and Ukiyo (2010) by Johannes Birringer, linking London and Tokyo.

\section{TELEMATIC PERFORMANCE:THE SPECTATOR}

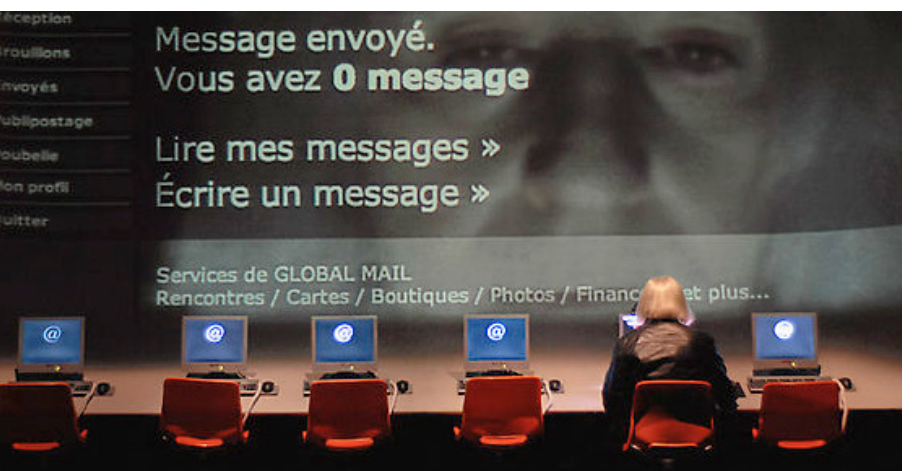

Fig. 1. A moment during the performance The Andersen Project (2006) by Canadian Robert Lepage. The computer interface, which the stage actor is using, is projected as background, thus allowing the audience to see the details of the screen. Photo: Emmanuel Valette.
Examples of low-tech telematic performance have recently started to emerge in alternative theatre and performance circles and also in circles that are part of the visual arts. There is Skype Duet (2011) by Brina Stinehelfer / Per Aspera Productions, linking a theatre venue in Berlin and a café in New York; Annie Abrahams' ON LOVE (2013) linking a theatre venue and nine English-speaking performer from their private homes located all over the world; Helen Varley Jamieson and Paula Crutchlow's makeshift (2010) linking two private homes.

Regarding space expansion, telematic performance aims at uniting two (or more) separate platforms into a unitary event, so interconnected that the one cannot take place without the other - the live and online, the physical and the virtual, the here and the remote. The way space is expanded in these cases is by the addition of the remote and abstract space of the Internet to the live performance site, where online activity takes place.

The Ethno-Cyberpunk Trading Post \& Curio Shop on the Electronic Frontier from 1994 is the first of a series of experiments where performance artists Guillermo Gómez Peńa and James Luna conducted ethnographic questionnaires online that were used as performance suggestions. In the performance, Gómez Peńa and Luna transformed their appearance and behaviour according to suggestion provided by gallery visitors, visitors watching a video-conference feed online, questionnaires and data uploaded by online visitors. The work aimed at revealing people's racism by inviting participants to share their favourite sexual jokes, fantasies and encounters with a person of colour that the performers represented. ${ }^{2}$

In reflection on the role of the online platform, Gómez Peña explains how the suggestions provided by online users were more "confessional, graphic and explicit" than the suggestions given by visitor on the site, which were more politically correct.

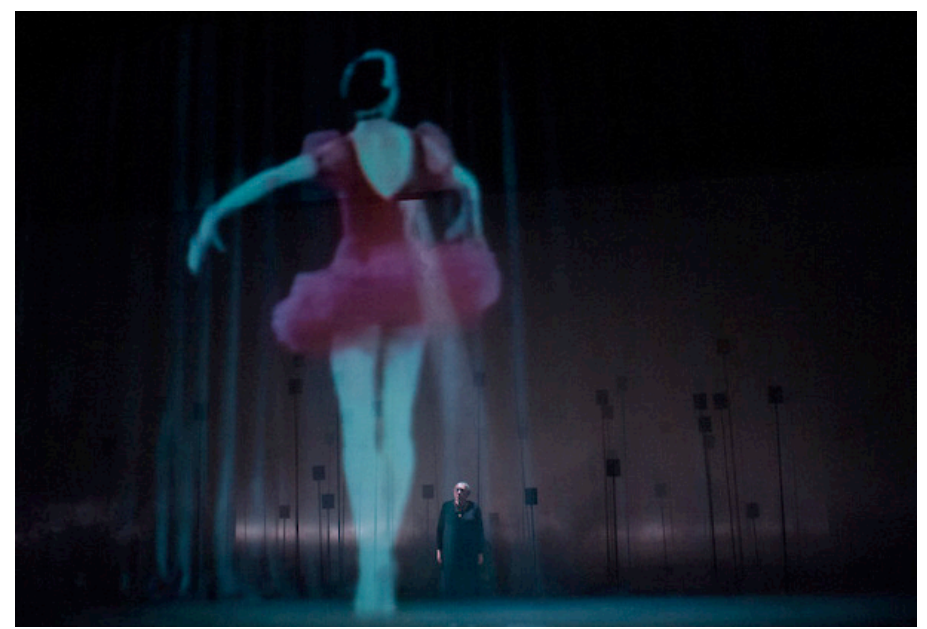

ig. 2. A moment during the performance Ghost Road (2013) by Fabrice Murgia of Belgium. The image of a dancing ballerina is projected onto a transparent screen located between the audience and the stage actor. Photo: Kurt Van Der Elst. 
Dixon, in reflection, argues that "the distance and anonymity provided by the artificially safe environment of the Internet short-circuited normal reserve and sensibility and fuelled more courage to reveal secrets and fantasies". ${ }^{22}$ On the other hand, Gómez Peña also mentions how this distance and anonymity also afforded online visitors the means to offer suggestions that were "outrageous", simply because they were not present and therefore could not experience the consequences of their instructions. ${ }^{23}$

One could argue that the anonymity provided by the online platforms benefited the performance by fostering audience participation and affording uncensored conversations where political correctness could have disabled the dialogue. Conversely, it could also be argued that it may limit the performance by invalidating those very conversations if they were not taken seriously by online users, since there were no direct consequences of their online actions.

It is the perceived "distance" by the audience and the anonymity that it affords, which seem to have an effect on the behaviour of the audience and, thus, on the activities that can happen in the performance. The distance between the physical performance space and the dispersed location of the spectators can be understood as a psychological space that can be used by the audience: they can remain observers, they can participate in a constructive way and help co-create the performance, they can challenge the performance by engaging in trolling behaviour, and so on. It is spectators who decide their investment in it. This imaginary line of possibility can be understood as a psychological space of freedom that can be used by the audience to transgress, perform or not: it is a space for reflection as well as for action.

The relevance of these findings to space expansion is that even though there is a very literal expansion of topographic space through telematic technologies (the audience is able to virtually connect with dispersed locations), the spaces where users are physically located do not seem to have an impact on the performance, if they are not physically present in the performance space. There is no attempt to incorporate the users' physical locations (and its physical characteristics) in the performance or to problematize those extended spaces (as opposed to pervasive performance, where - as we will see late in the article - extended space becomes a fundamental element in the performance as a whole).

Here, the function of space expansion is to cre ate a new kind of spectator-as-user: the online spectator. The figure of the online spectator resembles the notion of the "produser", (producer + user), an agent who blurs the boundaries between passive consumption and active production, and ofte alternates between the two roles. ${ }^{24}$ Psychological space is here used to describe the increased potentia for audience participation regulated by the rationale of Internet communication. The consequences of the expansion of space for the online spectato are important. First, $s /$ he does not have to go to the theatre, but the theatre goes to her. Second, even though $s /$ he has the option of behaving as a traditional spectator that "views", s/he is offered the option of participation by typing suggestions, comments or uploading digital materials. In this sense, the invitation to participate can be understood as a way to overcome the lack of the elements that frame a theatrical event as such - the actors, the venue, and the other spectators - in a space where none of that exists. The consequences for the actor are that $s /$ he puts her/himself in a vulnerable position as $s /$ he is inviting users to collaborate with her/him, knowing that $\mathrm{s} / \mathrm{he}$ would not have any control over the users' contributions. However, s/he can use thi as an artistic resource and challenge herself and the performance as in the example of González Peña and Luna.

\section{PERVASIVE PERFORMANCE:THE SPECTATOR} AS PLAYER

Pervasive performance is a hybrid emergent phenomenon that seeks to engage participants in collaborative events through a combination of gameplay, media and performance. I have defined it as "mixed-media events that combine gameplay with performance and use it as a platform for potential collaborative art making in public spaces for a playing audience".

Established examples are works by German $\mathrm{Ri}$ mini Protokoll such as Call Cutta in a Box (2008) and Outdoors (2011) and works by The British Blast Theory such as Can You See Me Now (2001) or Rider Spoke (2007).

Pervasive performance was born at the turn of the twentieth century out of the convergence of the fields of ubiquitous media, experimental game design and contemporary performance. As practitioners and designers started to incorporate mobile media into their productions - users were no longer fastened by cables to a computer - participant were able to move across public and private spaces, constantly connected, on the move, and tracked by GPS systems.

In this category, space is expanded by technology in a literal, territorial sense. These events normally take place partly inside of cultural institutions such as theatre houses, galleries or community centres, and partly outdoors. Mobile media are used as a way to expand the playground for performance out into the public space. Multiple and mobile subjects are dispersed and distributed while still connected to the performance (and in some cases to each other) via mobile devices. Technology expands the territory for performance from a concrete venue, where conventions regarding physical co-presence in a cultural institution operate, to the city space, where the audience is separated from each other and where they have to interact with the city and its inhabitants, a place where theatre conventions are blurred by social conventions of behaviour. However, can the space for performance be accounted for?

A project that explicitly aimed at training participants' "theatrical sensibility" in the public space was this author's Chain Reaction (2009 and 2011), ${ }^{2}$ which aimed at using public space - its objects, peoples and interactions - as source material and inspiration for participants to make theatre. As participants arrived in the start point, they were instructed to complete a number of creative missions in the city environment, such as creating a short movement piece in a park, or get passers-by to sing their favourite songs. Participants later returned to the starting point where they were asked to crosshatch the materials from the missions to devise a shor performance out of their experiences and materials collected on their journey. Every group performed its piece for the rest of the participants - other play- ers and the actors - and there was a final and informal vote to decide on 'the best' show.

Chain Reaction altered the conception of the audience in that it facilitated participants to engag with space in a way that brought forth its playful and theatrical possibilities, making them see space with new, fresh, and 'theatrical' eyes. Furthermore, it also generated a situation where the interaction with space would have aesthetic consequences in the performance as the materials collected were the main source to devise the performance pieces. In this sense, Chain Reaction sought to enhance the status of ordinary and everyday space - its routine and every-day activities - as legitimate materials for art-making while simultaneously lowering the threshold of participation so that players felt safe and secure playing with their own, familiar environments.

The crucial aspect of how space is expanded is the way in which moving the core action to the outdoors does not merely seek to re-locate the performance from the indoor of the theatre building to the outdoors, but rather seeks to explore the materiality of public spaces through play and performance. Jane McGonigal, when writing about ubiquitous games, argues that these games "mak players aware of the ludic possibilities of the world around them, exploring the site's objects, peoples and interactions" ${ }^{26}$ The same holds true for pervasive performance, where participants are challenged to discover the place's "hidden affordances" through "sensuous activation". ${ }^{27}$ This way, the participan becomes a fundamental part of the piece, with the capacity of being an agent that actively discovers, while simultaneously being enlightened in and about the place she is in.

The consequences of this type of expansion for the audience are significant. The audience becomes a "playing audience" that fills the artworks with content. While using public space to achieve this is not necessary, as playing audiences can also exist in enclosed private spaces - such as in som improvisation and ritual forms - it affords a double gesture: to have the audience playfully explore the artistic possibilities of the world around them (see what can be transformed into art), and also to bring forward their own personal, artistic vision of 
that world (through composing the materials of the world through performance). The role of the performers also changes here, transforming into a facilitation and support of the participants' playing activities, as performers become "orchestrators". ${ }^{28}$ In this sense, performers are not the ones providing content, but rather facilitate content production. ${ }^{2}$ Both roles, audience and performers, are blurred as they step into each other's tasks.

\section{CONCLUSION}

I have shown through the examples how space is expanded in very different ways in digital performance. In multimedia performance, space is expanded metaphorically, referring to the development of new sets of strategies for meaning making thanks to the combination of media and stage action; in telematic performance, it is expanded psychologically, referring to different types of actions that the lack of physical presence affords; whereas in pervasive performance, it is expanded in a literal, territorial sense, bringing in an environments' stimuli as added aesthetic elements. These different ways of expanding space impact the role of the audience, going from a "spectator-as-viewer" in multimedia performance, a distributed online spectator, or "spectator-as-user" in telematic performance, and a mobile "spectator-as-player" in pervasive performance. Even though space expansion may have other dramaturgical causes than the activation of the audience, the expansion of theatrical and ludic space implies redefining the role of the audience into active forms of engagement, a kind of "spectator-as-agent". This is helpful when revising Dixon's previous claim where he argued that there can be an expansion of theatrical space as long as there are "spectators-as-viewers" located in the extended spaces. But what do these radically new conceptions of the audience tell us about space and its expansion?

First, we learn that for space to expand in interesting ways, space does not only need to be able to contain or accommodate spectators, it must also be able to support and respond to actions by spectators. In this sense, space is no longer expanded by the presence of "spectators-as-viewers", but also by the capacity that practitioners have to design spaces that support actions and activities by the audience. That is: it is not about presence only, but mainly about participation

Second, the development of the "spectator as agent" can be understood as a strategy developed to compensate for the lack of physical co-presence that traditional performance offers. In other words the lack of physical co-presence requires the development of other strategies to create a sense of being part of a performance event. Although there might be other strategies to achieve this, the ones I have analysed here point towards participation by the audience (online visitors or players) as the glue that ties expanded spaces to the same performance event.

\section{NOTES AND REFERENCES}

In this article, I borrow Steve Dixon's broad definition on Digital Performance: "Digital performance concern the conjunction of computer technologies with the live performance arts, as well as gallery installations and computer platform web-based net.art, CD-ROMS and digital games where performance constitutes a central aspect of either the content (for example, through a focus on a moving, speaking or otherwise 'performing' human figure) or form (for example, interactive installations that prompt visitors to 'perform' actions rather than simply watch a screen and 'point and click'." In Digital Performance: A History of New Media in Theater, Dance, Performance Art, and Installation, MIT Press, Cambridge, MA 2007, p. x.

2 Greg Giesekam, Staging the Screen: The Use of Film and Video in Theatre, Palgrave MacMillan, New York 2007 p. 8.

3 The concept of gameplay comes from the field of game design and it refers to the type of interaction between players and a game. Richard Rouse defines it as "the degree and nature of the interactivity that a game includes. i.e., how players are able to interact with the game-world and how that game-word reacts to the choices players make." In Game Design: Theory and Practice, Wordware Publishing, Sudbury, MA 2005, p. xx.

4 Christopher Balme, The Cambridge Introduction to The atre Studies, Cambridge University Press, Cambridge 2008, p. 47.

5 Ibid., p. 49

6 Dixon, op. cit., p. 335

7 Marvin Carlson, Places of Performance: The Semiotics of Theatre Architecture, Cornell University Press, Ithaca, NY 1989, p. 6.

8 Christopher Balme, The Theatrical Public Sphere, Cambridge University Press, Cambridge 2014. See chapter 6, pp. 174-202.

9 This idea is extensively discussed by social psychologis Sherry Turkle in her book Alone Together: Why We Expec More From Technology and Less From Each Other, Basic Books, New York 2011

10 Dixon, op. cit., p. 413.

11 "Theater/Dance and New Media and Information Technologies", presented at the Working Groups on Dance and Drama, Research Group on Reorganisation of Professional Arts Education, Amsterdam, 1998, http:// www.art.net/-dtz/scott3.html (accessed 14 February 2014).
12 "Being Here: Presence/Remote Presence Within Live and Media-Based Performance", University of Californi at Berkeley, 22 April 2007.

13 Steve Benford and Gabriella Giannachi, Performing Mixed Reality, MIT Press, Cambridge 2011

14 "Trajectories indicate predicted and actual itineraties through mixed reality experiences. These emerge as a result of diverse types of navigation, journeying an mapping $[\ldots]$ Trajectories are paths of observation and experience that facilitate one's route through it", in Benford and Giannachi, op. cit., p. 15

15 Ibid., p. 37.

16 Hans-Thies Lehmann, Postdramatic Theatre, Routledge, London 2006.

7 These practitioners have created work on both sides of the spectrum. Robert Lepage and The Builders Association generally produce plays with a storyline, while The Wooster Group is generally associated with postdramatic performances. Robert Wilson is an example of a directo who has engaged with both traditions throughout hi career. On the one hand he has directed 'Aristotelian' dramas, staging Shakespeare and Ibsen, but he has als engaged in experimental and postdramatic practices. As a matter of fact, Wilson's experimental work is used as basis for analyses by Lehmann in the construction of the aestherics of postdramatic theatre.

18 Dixon, op. cit., p. 335

19 Ibid., p. 336

20 Erik Geelhoed, "User Requirements in Immersive Med ated Performance Spaces", presented at the Remote Encounters Conference, Cardiff, 2013, http://remote-en counters.tumblr.com/schedule (accessed 8 May 2013).

21 Dixon, op. cit., p. 500

22 Ibid., p. 501.

23 Ibid., p. 502.

24 The concept of the "produser" was coined by Australian media scholar Axel Bruns, who argued for the rise of new products and new agents in the digital age. He claimed that, as user-led content creation grows and proliferates in a variety of online environments - with seminal examples such as Wikipedia and YouTube - the concept of the user proves limiting. He pushed for an expansion of the concept to embrace a new model of shared production, where amateurs are not relegated to consumptio of products created by specialists, but actively participate in production of such products. In Axel Bruns, Blogs, Wikipedia, Second Life, and Beyond. From Production to 
Produsage, Peter Lang, New York 2008. Also see Lawrence Lessig, Remix: Making Art and Commerce Thrive in the Hybrid Economy, Penguin Press, New York 2008.

25 The first performance took place in Berkeley in 2009, in different sites, all located in public space, while the second set of performances took place in Trondheim, Norway 2011, partly in an experimental theatre house and partly outdoors. The projects are documented on the author's webpage: http://www.elenaperezrodriguez. com/\#!art-work.

26 Jane E. McGonigal, "This Might Be a Game: Ubiquitous Play and Performance at the Turn of the Twenty-First Century", PhD thesis, University of California, 2006, p. 456.

7 McGonigal, op. cit., p. 457.

28 See discussion "Orchestrating Mixed Reality" in Benford and Giannachi, op. cit., pp. 215-24.

29 Grant H. Kester, Conversation Pieces: Community and Communication in Modern Art, University of California Press, Berkeley 2004. 